DOI: $10.4274 /$ jarem.galenos.2019.2785

J Acad Res Med 2020;10(2):189-91

\title{
Cervical Lipoleiomyoma: Case Report
}

\author{
(D) Veli Mihmanlı, (D) Ali Emre Atik \\ University of Health Sciences Turkey, Okmeydanı Training and Research Hospital, Clinic of Obstetrics and Gynecology, İstanbul, Turkey \\ Cite this article as: Mihmanlı V, Atik AE. Cervical Lipoleiomyoma: Case Report. J Acad Res Med 2020;10(2):189-91
}

\begin{abstract}
Lipoleiomyomas are uncommon benign neoplasms composed of various mixtures of long intersecting bundles of bland smooth-muscle cells and mature adipocytes. These tumors are most commonly located in the uterine corpus, but rarely may be found in other locations, including the cervix, ovary, broad ligament, and retroperitoneum.
\end{abstract}

Keywords: Lipoleiomyoma, cervical

\section{INTRODUCTION}

Uterine lipoleiomyomas are rare (0.03\%-0.20\%) benign neoplasms known as a specific type of leiomyoma. These tumors are composed of a mixture of smooth muscle cells and mature adipocytes. They are most commonly found in the uterine corpus, but rarely can found in other localizations, such as the cervix, ovary, broad ligament, and retroperitoneum (1).

Most of the patients are asymptomatic peri or postmenopausal women. In fact, uterine lipoleiomyomas are clinically similar to leiomyomas and do not require treatment if they are asymptomatic. These tumors can be mixed with other gynecological conditions such as mature teratoma, welldifferentiated liposarcoma and atypical lipoma $(2,3)$. Therefore, surgical excision of these tumors and definitive histopathological diagnosis are important.

Here, an extremely rare case of cervical lipoleiomyoma diagnosed with postoperative histopathological examination in the premenopausal patient is presented with the consent of the patient.

\section{CASE PRESENTATION}

A 39-year-old G2P2 female patient applied with complaints of inguinal pain, which was more significant during sexual intercourse. In bimanual examination, a hard, solid cervical mass with a diameter of 7-8 cm was detected, which was protruded into the vagina, the borders of which were not clearly separated from the uterus. Magnetic resonance imaging (MRI) showed mass lesions with smooth lobulated contours filling the vagina, pushing the cervix into the superiora and anteriorly, showing intense contrast involvement in heterogeneous T2 signal intensity in a measure of $83 \times 73 \times 60 \mathrm{~mm}$ (Figure 1). Hemoglobin: $10.3 \mathrm{~g} / \mathrm{dL}$, hematocrit: $31.2 \%$, serum glutamic oxaloacetic transaminase: $20 \mathrm{U} / \mathrm{L}$, serum glutamic pyruvic transaminase: $16 \mathrm{U} / \mathrm{L}$, cancer antigen (CA)125; $20.1 \mathrm{U} / \mathrm{mL}$, carcinoembryonic antigen: $1.18 \mathrm{ng} / \mathrm{mL}, \mathrm{CA} 19-9: 8.6 \mathrm{ng} / \mathrm{mL}, \mathrm{CA}: 15-326.8 \mathrm{U} /$ $\mathrm{mL} .8 \mathrm{~cm}$ diameter solid mass originating from the cervical region was detected in the patient who was operated with pfannenstiel incision under general anesthesia. Hysterectomy and bilateral salpingectomy were performed (Figure 2). The patient was discharged on the third postoperative day, and

ORCID IDs of the authors: V.M. 0000-0001-8701-8462; A.E.A. 0000-0003-4633-0032. 


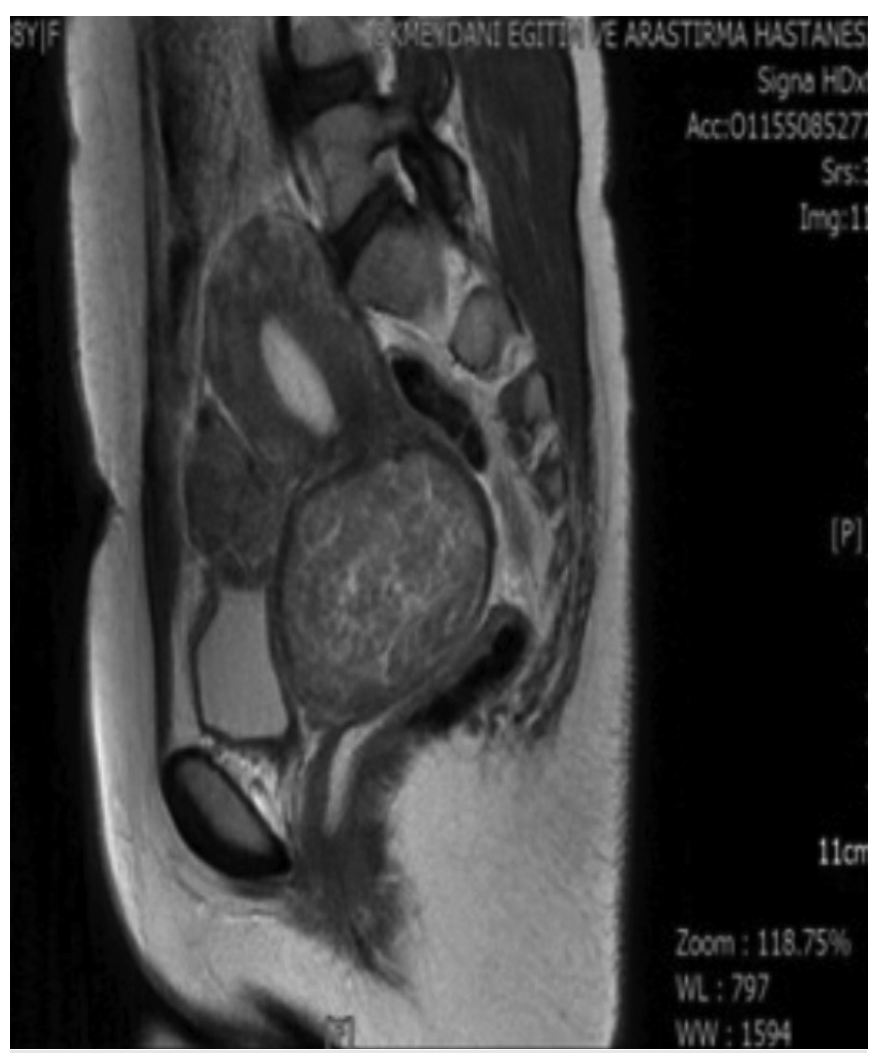

Figure 1. Preoperative magnetic resonance image

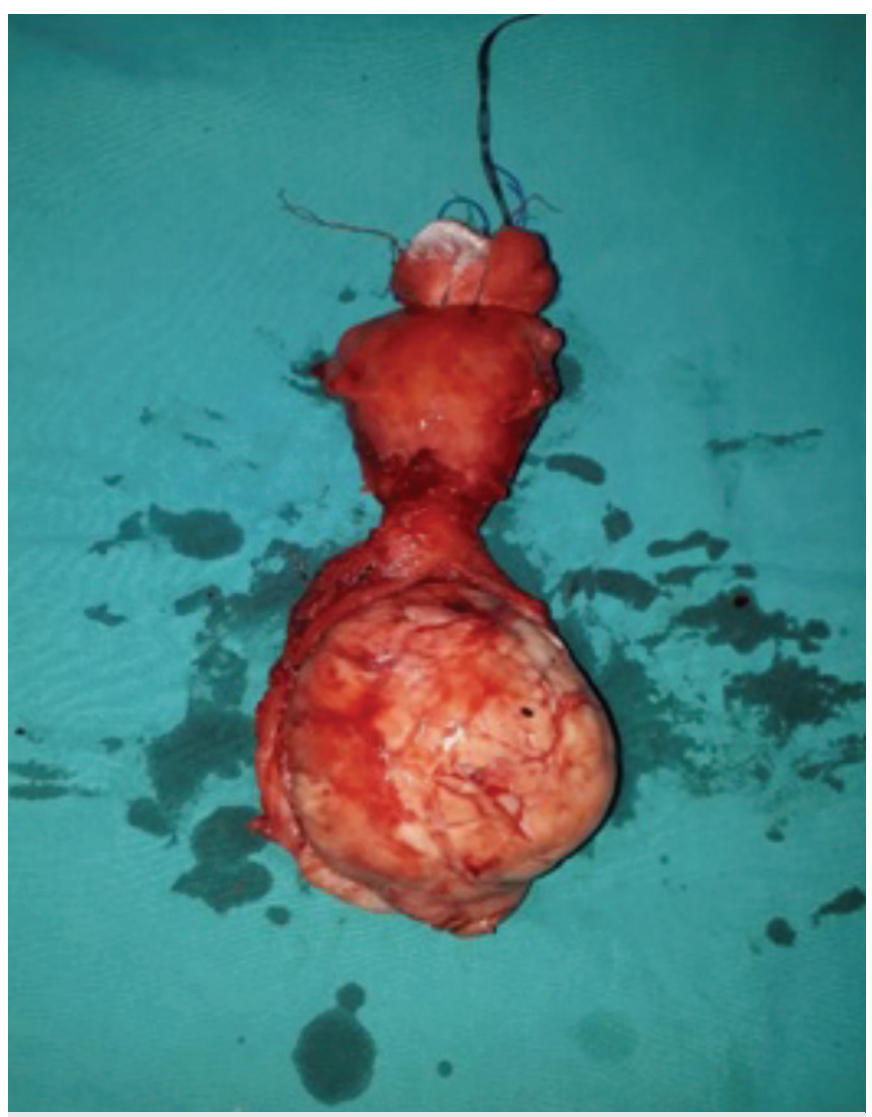

Figure 2. Postoperative histopathological specimen the result of postoperative pathology was reported as cervical lipoleiomyom.

Informed consent was obtained.

\section{DISCUSSION}

Cervical leiomyoma is the most common cervical benign tumor that develops in the cervical muscle tissue, usually $0.5-1 \mathrm{~cm}$ diameter, single, straight structure, hard and similar to uterine myomas. Cervical fibroids constitute 1-2\% of total fibroids and are observed in 3 different ways: interstitial, supravaginal and polypoidal. Supravaginal fibroids can push the uterus to the superior by surrounding the entire cervical canal. They can also be unilateral or bilateral, intramural or subserosal and can extend into the pelvis. Symptoms may differ depending on the direction of growth of the fibroid. Growing fibroids can cause symptoms related to mechanical pressure in neighboring organs, causing dysuria, urinary incontinence, ureteral obstruction, dyspareunia, or blockage of the cervix (4).

Uterine lipoleiomyoma is a rare mesenchymal neoplasm and is often described as a variant of uterine leiomyoma. It constitutes less than $0.2 \%$ of benign uterine tumors. Lipoleiomyoma consists of a mixture of smooth muscle and mature adipose tissue. The origin of the lipomatosis lesions of the uterus is a matter of debate; possible causes are the wrong placement of adipose cells in the embryological period, metaplasia of muscle and connective tissue cells to adipose cells, lipocytic differentiation of primitive connective tissue cells, infiltration of perivascular adipose cells around the vessel during the operation or connective tissue degeneration (5).

Imaging plays an important role in intrauterine localization and determination of adipose tissue content. In ultrasonographic examination, it presents as hyperechoic masses partially covered with a hypoechoic area. The hypoechoic area is interpreted as the myometrium surrounding the adipose tissue component. In computed tomography, the mass lesion is observed as the dominant hypodense area from the well-limited adipose tissue that separates from the uterus. In MRI examination, lipomatous component is observed in high signal intensity on T1-weighted images. The lipomatous component can be confirmed using the adipose suppression technique (6).

Similar uterine tumors that should be considered in differential diagnosis are angiolipoma, angiomyolipoma, lipoid degenerated leiomyoma, atypical lipoma and well-differentiated liposarcoma. Immunocytochemical studies confirm the complex histogenesis of these tumors that may arise from mesenchymal immature cells or direct transformation of smooth muscle cells into adipocytes. Additional gynecological malignancies from the uterus, cervix or ovaries have been reported in $18.8 \%$ of patients. Therefore, patients with uterine lipoleiomyomas should be subjected to detailed clinical and pathological evaluation in order not to overlook the coexistent gynecological malignancy. As a result of long-term follow-up of uterine lipoleiomyomas, it has been shown 
that such cases progress in benign character and that such cases do not cause any recurrence or death due to disease as isolated (7).

\section{CONCLUSION}

Although cervical lipoleiomyomas are much more rare than those of uterine origin, the symptoms of both are similar to typical leiomyomas. It is frequently seen in perimenopausal or postmenopausal women, rarely in premenopausal women. The definitive diagnosis is made by postoperative histopathological examination.

Informed Consent: It was obtained.

Peer-review: Externally peer-reviewed.

Author Contributions: Concept - V.M., A.E.A.; Design - V.M., A.E.A.; Supervision - V.M., A.E.A.; Resources - V.M.; Materials - V.M.; Data Collection and/or Processing - V.M., A.E.A.; Analysis and/or Interpretation - V.M.; Literature Search - V.M.; Writing Manuscript -V.M., A.E.A.; Critical Review - V.M., A.E.A.
Conflict of Interest: The authors have no conflict of interest to declare.

Financial Disclosure: The authors declared that this study has received no financial support.

\section{REFERENCES}

1. Oh SR, Cho YJ, Han M, Bae JW, Park JW, Rha SH. Uterine Lipoleiomyoma in peri or postmenopausal women. J Menopausal Med 2015; 21: 165-70.

2. Wang $X$, Kumar $D$, Seidman JD. Uterine lipoleiomyomas: a clinicopathologic study of 50 cases. Int J Gynecol Pathol. 2006; 25: 23942.

3. Aung T, Goto M, Nomoto M, Kitajima S, Douchi T, Yoshinaga M. Uterine lipoleiomyoma: a histopathological review of 17 cases. Pathol Int. 2004; 54: $751-8$.

4. Sharma $S$, Ahluwalia $C$, Mandal AK, A rare incidental case of lipoleiomyoma cervix. J. Health Sci. 2015; 2: 186-90.

5. Bolat F, Kayaselçuk F, Canpolat T, Erkanlı S, Tuncer I. Histogenesis of lipomatous component in uterine lipoleiomyomas. Turkish Journal of Pathology 2007; 23: 82-6.

6. Erhan SŞ, Keser SH, Soylu Boy FN, Çom Ç. Serviks uteri lokalizasyonlu lipoleiomyom: Olgu sunumu, Okmeydanı Tıp Dergisi 2017; 33: 50-3.

7. Devarmani SS, Laheru VB. Uterine lipoleiomyoma-a rare case report with review of literature. Journal of Evolution of Medical and Dental Sciences 2013; $2 ; 352-5$ 